\title{
Eye Rubbing and Keratoconus: A Literature Review
}

${ }^{1}$ Elizabeth Hawkes, ${ }^{2}$ Mayank A Nanavaty

\begin{abstract}
Keratoconus is a progressive corneal ectactic condition that can lead to visual loss. Despite being the most common cause for keratoplasty in the developed world the aetiology is unknown. It is thought to be multifactorial, with genetic and environmental factors implicated. The association of eye rubbing and pathogenesis of keratoconus has been well documented. In this review, we collate the existing literature and summarize the current knowledge of the role of eye rubbing in the pathogenesis of keratoconus.
\end{abstract}

Keywords: Keratoconus, Eye rubbing, Corneal ectasia.

How to cite this article: Hawkes E, Nanavaty MA. Eye Rubbing and Keratoconus: A Literature Review. Int J Kerat Ect Cor Dis 2014;3(3):118-121.

\section{Source of support: Nil}

Conflict of interest: None

\section{INTRODUCTION}

Keratoconus, first described in 1854 by Nottingham, is a progressive disease which presents with blurred vision secondary to irregular astigmatism. ${ }^{1}$ It is an ectatic disorder leading to thinning of the cornea, in the absence of inflammation, which usually occurs bilaterally. ${ }^{2,3}$ The prevalence of keratoconus varies and due to advances in corneal imaging, it is being diagnosed earlier and more commonly nowadays. In the US population, a prevalence of 1 per 2,000 has been calculated, however, other epidemiological studies have shown a prevalence ranging from 0.3 per 100,000 in Russia to 2300 per 100,000 in Central India (0.0003-2.3\%). ${ }^{4-6}$ This variability is thought to be due to several factors, such as ethnicity, geographical location and family history. ${ }^{7}$ Widespread biochemical changes are known to occur during the development and progression of keratoconus, however, the etiology of these events are multifactorial with both genetic and environmental factors. ${ }^{8}$ Ethnicity is also considered important, with Asians having keratoconus earlier and aggressive compared to Caucasians. $^{9}$

\footnotetext{
${ }^{1}$ Resident, ${ }^{2}$ Consultant Ophthalmic Surgeon

1,2 Sussex Eye Hospital, Brighton and Sussex University Hospitals NHS Trust, United Kingdom
}

Corresponding Author: Mayank A Nanavaty, Consultant Ophthalmic Surgeon, Sussex Eye Hospital, Brighton and Sussex University Hospitals NHS Trust, United Kingdom Phone: 07947166134, e-mail: mayank.nanavaty@bsuh.nhs.uk
A genetic theory has been well-documented, in one study $14 \%$ of patients with a known diagnosis of keratoconus had a positive family history. ${ }^{10}$ Furthermore, larger percentages of patients with a positive family history for keratoconus have been shown to have early topographical changes suggestive of keratoconus despite of being visually asymptomatic. ${ }^{11,12}$ Monozygotic twin and familial studies have also shown increased concordance for disease. ${ }^{13-15}$ Genome wide association studies have located the 2q21.3 region as being highly susceptible. ${ }^{16}$ A specific single gene mutation, however, has proved elusive. It is probable that numerous genes contribute or are responsible for increasing the risk for developing keratoconus. ${ }^{17-22}$

The association of keratoconus with numerous syndromes is also well acknowledged. These range from connective tissue disorders, such as Marfan's syndrome, to those involving significant atopic change. ${ }^{8}$ The syndromes relating to atopic change and eczema are particularly of interest for the purpose of this review, as they are thought to induce keratoconus due to the increased propensity to rub the eyes. Examples of such syndromes include Down's syndrome, hyper-IgE syndrome, ichthyosis, and Turner syndrome. ${ }^{8}$ There is also an association of eye rubbing, and secondary keratoconus, with those suffering from low mental function, which can be a defining feature of many other systemic genetic diseases, such as albinism. ${ }^{23}$ Furthermore, those with a compulsion to eye rub, such as Tourette's syndrome patients have been shown to have an increased risk of keratoconus. ${ }^{24}$

It has been postulated that eye rubbing may be responsible for the development of keratoconus, possibly as a two hit hypothesis, in those with an increased genetic predisposition. ${ }^{25,26}$ The early description of such an association was in 1976 by Karseras et al. ${ }^{27}$ Excessive eye rubbing relates to an activity which has a frequency, vigor, and time period which is longer than normal. In this review, we highlight the current literature on eye rubbing and corneal changes in keratoconus.

\section{EYE RUBBING AS A CAUSE FOR KERATOCONUS}

Although the underlying reason for eye rubbing varies, it would seem that this chronic persistent habit has a major role in disease development. The youngest case in the literature describes a 4-year-old girl who developed 
bilateral keratoconus after persistent long-term eye rubbing. ${ }^{28}$ Various other case series and reports have drawn the association between oculodigital massage and keratoconus onset. ${ }^{29-33}$ Subjective reporting of asymmetric eye rubbing has also been correlated with worsening of corneal curvature. ${ }^{34}$ Keratoconus was found to be associated with hand dominance in a case of monocular keratoconus in patient with bilateral eyerubbing. ${ }^{35}$

A patient suffering from Tourette's syndrome with a compulsion to rub the eyes developed severe bilateral keratoconus and progressed to right eye phthisis in 4 years. ${ }^{36}$ Psychogenic eye rubbing, chronic compulsive eye rubbing, resulted in the development of keratoconus after 14 months. This was despite treatment with medication and electroconvulsive therapy. ${ }^{29}$ Another interesting case report described a recurrence of keratoconus in a patient who had undergone penetrating keratoplasty, which was deemed to be secondary to rubbing of the eyes. ${ }^{37}$

A multivariate logistic analysis in a study showing the increased prevalence of disease in patients with a history of parental consanguinuity, showed that eye rubbing is a significant risk factor in the development of keratoconus. ${ }^{38}$ Another paper surveyed 240 patients with known keratoconus and showed $65.6 \%$ had a history of eye rubbing when questioned. ${ }^{39}$ Similar incidences of eye rubbing in cohorts of keratoconus patients have been shown in other studies. ${ }^{40-42}$ The association of eye rubbing was shown to be higher (91.8\%) in a cohort of 49 children, deemed secondary to either atopy or induced ametropia. ${ }^{43}$

An interesting study analyzed a random cohort of 92 medical students in Lebanon, 3 of whom had a known diagnosis of keratoconus. Anterior topography was performed and found a keratoconus prevalence of $3.3 \%$, which was larger than the $2.2 \%$ known sufferers. A questionnaire of the participants revealed $12 \%$ had a family history of keratoconus, but also found that eye rubbing and atopy were not significantly related to the presence of keratoconus. ${ }^{44}$

These reports have demonstrated that abnormal eye rubbing can be psychogenic with compulsive, unprovoked rubbing or secondary to irritating symptoms of itching or dryness.

\section{PHYSICAL CORNEAL CHANGES SECONDARY TO EYE RUBBING IN KERATOCONUS}

Several mechanisms have been proposed for the development of keratoconus secondary to eye rubbing. ${ }^{45}$ The cornea is elastic and, therefore, susceptible to changes in shape. The force and frequency of rubbing are key fac- tors associated with corneal eye rubbing related changes. Both vigorous knuckle-grinding rubbing and repetitive gentle rubbing have been linked to the development of keratoconus. $^{33}$

Contact lens wear is known to be associated with increased eye-rubbing in healthy controls. The stimulus is thought be irritation, itching and dryness on removal of lenses. Patients with keratoconus wear rigid contact lenses, therefore, leaving the corneal epithelium more susceptible to rubbing related trauma. ${ }^{25}$

Temperature is also considered to be associated with corneal remodelling. On eyelid closure, corneal temperature increases due to the close proximity of the palpebral conjunctiva and the circulatory warmth from its vasculature. ${ }^{45}$ Animal studies of rubbing, have shown a marked inflammatory response in the palpebral conjunctiva. It is possible that there is upregulation of collagenase activity during periods of rubbing related temperature spikes. ${ }^{45}$

As discussed later, intraocular pressure (IOP) changes with eye rubbing can also potentially explain the development of keratoconus. Large fluctuations in IOP could lead to indirect traumatization to keratoctyes and thus the onset of keratoconus. ${ }^{46}$

\section{PATHOLOGICAL CHANGES SECONDARY TO EYE RUBBING IN KERATOCONUS}

The underlying pathophysiological mechanism for corneal change in keratoconus is thought to be an imbalance between keratocyte apoptosis and keratocyte proliferation. ${ }^{47,48}$ There is also upregulation of interlukein- 1 in corneal fibroblasts in eyes with keratoconus. It is thought that increased sensitivity of keratocytes to interleukin-1 causes gradual loss of stromal mass. This process can be secondary to contact lens associated trauma or eye rubbing. ${ }^{49}$ Keratocyte density has been shown to be reduced in noncontact lens wearing individuals following 10 seconds of light rubbing using one finger repeated 30 times in a 30 minute period. ${ }^{49}$ Hollingsworth et al have demonstrated that reduction of anterior and posterior keratocyte density is significantly associated with eye rubbing. ${ }^{50}$ Firm rubbing in humans has shown to induce ocular chemosis and hyperemia. ${ }^{35}$ Patients with keratoconus are, therefore, susceptible to corneal remodeling and thinning due to damage from contact lens wear and eye rubbing.

Inflammatory markers are also known to contribute to the pathogenesis of keratoconus secondary to eye rubbing. Balasubramanian et al. used specific enzymelinked immunosorbent assays to measure the amount of inflammatory markers 60 seconds after eye-rubbing in normal subjects. ${ }^{51}$ They found an increased expression 
in tear matrix metalloproteinase-13, interleukin-6 and tumour necrosis factor- $\alpha$ in normal subjects. There was no significant change in collagenase activity. ${ }^{51}$ These inflammatory changes after rubbing are thought to contribute to the pathogenesis. ${ }^{52}$

\section{IMPORTANT OCULAR COMPLICATIONS SECONDARY TO EYE RUBBING IN KERATOCONUS}

In those patients with confirmed keratoconus, the continuation of eye rubbing has been shown to raise the likelihood of developing acute hydrops in children as young as 9 years of age ${ }^{53-56}$ For this reason, the development of behavior modification written guides has been utilized to slow the rate of ectasia progression and complications, and is particularly important in those with mental handicap. ${ }^{57,58}$ The finding of the development of acute hydrops secondary to chronic rubbing suggests that it may not be a spontaneous event. The mechanical stress of rubbing may be the cause of the development of hydrops in keratoconus. It is also important to note that progression of keratoconus to complications such as perforation may not be related to eye rubbing. ${ }^{59}$

Aside from its association with keratoconus, there have been other reports of complications occurring secondary to eye rubbing. Spikes in the IOP have been described secondary to indentation of the cornea following rubbing. This can be problematic due to the chronic nature of eye rubbing and the potential for development or worsening of axial myopia and glaucoma. ${ }^{60}$ Gentle and firm eye rubbing are able to temporarily increase the IOP two, and four fold respectively. ${ }^{61}$ Massaging of a rabbit eye in vivo has produced an IOP of $150 \mathrm{~mm} \mathrm{Hg}$, although, whether this level would be possible in humans is difficult to establish. ${ }^{62}$ These rubbing forces causing IOP fluctuation secondary to indention of the cornea are likely to be associated with corneal curvature transfer and development or progression of keratoconus. ${ }^{45}$

\section{CONCLUSION}

The association of eye rubbing and keratoconus is established and well documented. It would seem that a genetic predisposition, combined with repetitive eye rubbing are a risk factor for the development of keratoconus. The reason for eye rubbing seems to be independent of the physical damage that eye rubbing itself causes. However, the effect of short duration eye rubbing on healthy individuals remains unknown. Further research is, therefore, warranted on whether corneal topography may be temporarily altered in the acute phase of eye rubbing.

\section{REFERENCES}

1. Nottingham J. Practical observations on conical cornea, and on the short sight, and other defects of vision connected with it. London: J Churchill 1854.

2. Krachmer JH, Feder RS, Belin MW. Keratoconus and related non-inflammatory corneal thinning disorders. Surv Ophthalmol 1984;28:293-322.

3. Rabinowitz YS. Keratoconus. Surv Ophthalmol 1998;42: 297-319.

4. Kennedy RH, Bourne WM, Dyer JA. A 48-year clinical and epidemiologic study of keratoconus. Am J Ophthalmol 1986; 101(3):267-273.

5. Jonas JB, Nangia V, Matin A, Kulkarni M, Bhojwani K. Prevalence and associations of keratoconus in rural maharashtra in central India: the central India eye and medical study. Am J Ophthalmol 2009;148(5):760-765.

6. Gorskova EN, Sevostianov EN. Epidemiology of keratoconus in the Urals. Vestn Oftalmol 1998;114(4):38-40.

7. Gokhale NS. Epidemiology of keratoconus. Indian J Ophthalmol 2013;61(8):382-383.

8. Sugar J, Macsai MS. What causes keratoconus? Cornea 2012;31(6):716-719.

9. Kok YO, Tan GF, Loon SC. Review: keratoconus in Asia. Cornea 2012;31(5):581-593.

10. Wagner H, Barr JT, Zadnik K. Collaborative longitudinal evaluation of keratoconus (CLEK) study: methods and findings to date. Cont Lens Anterior Eye 2007;30:223-232.

11. Kaya V, Utine CA, Altunsoy M, et al. Evaluation of corneal topography with Orbscan II in first-degree relatives of patients with keratoconus. Cornea 2008;27:531-534.

12. Abstract: Itoi M, Hisae M, Tsuda N, et al. Corneal shape of familial members of keratoconis patients Presented at: 2011 ARVO Annual Meeting; April 30 to May 5, 2011; Fort Lauderdale. A1082-D706.

13. McMahon TT, Shin JA, Newlin A, et al. Discordance for keratoconus in two pairs of monozygotic twins. Cornea 1999;18:444-451.

14. Abstract: Liskova P, Willoughby CE, George S, et al. Phenotype and hereditability of keratoconus in twins. Presented at: 2011 ARVO Annual Meeting; April 30 to May 5, 2011; Fort Lauderdale. A1094-D718.

15. Abstract: Oleynikov YS, Rabinowitz YS. A case of keratoconus in 3 siblings from different mothers but the same father. Presented at: 2009 ARVO Annual Meeting; May 2 to May 7, 2009; Fort Lauderdale. A3546-D932.

16. Abstract: Li X, Bykhovskaya Y, Haritunians T, et al. Several susceptible regions are associated with keratoconus using genome-wide association and confirmation panels. Presented at: 2011 ARVO Annual Meeting; April 30 to May 5, 2011; Fort Lauderdale. A4385.

17. Heon E, Greenberg A, Kopp KK, et al. VSX1: a gene for posterior polymorphous dystrophy and keratoconus. Hum Mol Genet 2002;11:1029-1036.

18. Tang YG, Picornell Y, Su X, et al. Three VSX1 gene mutations, L159M, R166W, and H244R, are not associated with keratoconus. Cornea 2008;27:189-192.

19. Udar N, Atilano SR, Small K, et al. SOD1 haplotypes in familial keratoconus. Cornea 2009;28:902-907.

20. Adachi W, Mitsuishi Y, Terai K, et al. The association of HLA with young-onset keratoconus in Japan. Am J Ophthalmol 2002;133:557-559.

21. Bisceglia L, De Bonis P, Pizzicoli C, et al. Linkage analysis in keratoconus: replication of locus 5 q21.2 and identification of other suggestive loci. Invest Ophthalmol Vis Sci 2009;50: 1081-1086. 
22. Tang YG, Rabinowitz YS, Taylor KD, et al. Genomewide linkage scan in a multigeneration Caucasian pedigree identifies a novel locus for keratoconus on chromosome 5q14.3-q21.1. Genet Med 2005;7:397-405.

23. Haugen $\mathrm{OH}$. Keratoconus in the mentally retarded. Acta Ophthalmol (Copenh) 1992;70(1):111-114.

24. Mashor RS, Kumar NL, Ritenour RJ, Rootman DS. Keratoconus caused by eye rubbing in patients with Tourette Syndrome. Can J Ophthalmol 2011;46(1):83-86.

25. McMonnies CW, Boneham GC. Keratoconus, allergy, itch, eye-rubbing and hand-dominance. Clin Exp Optom 2003;86(6):376-384.

26. McMonnies CW. Abnormal rubbing and keractectasia. Eye Contact Lens 2007;33(p Pt 1):265-271.

27. Karseras AG, Ruben M. Aetiology of keratoconus. Br J Ophthalmol 1976;60(7):522-525.

28. Gunes A, Tok L, Tok O, Seyrek L. The youngest patient with bilateral keratoconus secondary to chronic persistent eye rubbing. Semin Ophthalmol 2014 Feb 7 [Epub ahead of print].

29. Koenig SB. Bilateral recurrent self-induced keratoconus. Eye Contact Lens 2008;34(6):343-344.

30. Diniz CM, Tzelikis PF, Rodrigues Júnior A, Alvim Hda S, Dantas RR, Figueredo AR. Unilateral keratoconus associated with continual eye rubbing due to nasolacrimal obstructioncase report. Arq Bras Oftalmol 2005;68(1):122-125.

31. Jafri B, Lichter H, Stulting RD. Asymmetric keratoconus attributed to eye rubbing. Cornea 2004;23(6):560-564.

32. Ionnidis AS, Speedwell L, Nischal KK. Unilateral keratoconus in a child with chronic and persistent eye rubbing. Am J Ophthalmol 2005;139(2):356-357.

33. Lindsay RG, Bruce AS, Gutteridge IF. Keratoconus associated with continual eye rubbing due to punctual agenesis. Cornea 2000;19(4):567-569.

34. Zadnik K, Steger-May K, Fink BA, Joslin CE, Nichols JJ, Rosenstiel CE, Tyler JA, Yu JA, Raasch TW, Schechtman KB; CLEK Study Group. Collaborative Longitudinal Evaluation of Keratoconus. Between-eye asymmetry in keratoconus. Cornea 2002;21(7):671-679.

35. Rabinowitz YS,Nesburn AB, McDonnellPJ.Videokeratography of the fellow eye in unilateral keratoconus. Ophthalmology. 1993 Feb;100(2):181-186.

36. Kandarakis A, Karampelas M, Soumplis V, Panos C, Makris N, Kandarakis S, Karagiannis D. A case of bilateral selfinduced keratoconus in a patient with tourette syndrome associated with compulsive eye rubbing: case report. BMCOphthalmol 2011;11:28.

37. Yeniad B, Alparslan N, Akarcay K. Eye rubbing as an apparent cause of recurrent keratoconus. Cornea 2009;28(4):477-479.

38. Gordon-Shaag A, Millodot M, Essa M, Garth J, Ghara M, Shneor E. Is consanguinity a risk factor for keratoconus? Optom Vis Sci 2013;90(5):448-454.

39. Shneor E, Millodot M, Blumberg S, Ortenberg I, Behrman S, Gordon-Shaag A. Characteristics of 244 patients with keratoconus seen in an optometric contact lens practice. Clin Exp Optom 2013;96(2):219-224.

40. Khor WB, Wei RH, Lim L, Chan CM, Tan DT. Keratoconus in Asians: demographics, clinical characteristics and visual function in a hospital-based population. Clin Experiment Ophthalmol 2011;39(4):299-307.

41. Owens H, Gamble G. A profile of keratoconus in New Zealand. Cornea 2003;22(2):122-125.

42. Weed KH, MacEwen CJ, Giles T, Low J, McGhee CN. The Dundee University Scottish Keratoconus study: demo- graphics, corneal signs, associated diseases, and eye rubbing. Eye (Lond). 2008;22(4):534-541.

43. Léoni-Mesplié S, Mortemousque B, Mesplié N, Touboul D, Praud D, Malet F, Colin J. Epidemiological aspects of keratoconus in children. J Fr Ophtalmol 2012;35(10):776-785.

44. Waked N, Fayad AM, Fadlallah A, El Rami H. Keratoconus screening in a Lebanese students' population. J Fr Ophtalmol 2012;35(1):23-29.

45. McMonnies CW. Mechanisms of rubbing-related corneal trauma in keratoconus. Cornea 2009;28(6):607-615.

46. Bron AJ. The architecture of the corneal stroma. Br J Ophthalmol. 2001;85(4):379-381.

47. Wilson SE, He YG, Weng J, Li Q, McDowall AW, Vital M, Chwang EL. Epithelial injury induces keratocyte apoptosis: hypothesized role for the interleukin-1 system in the modulation of corneal tissue organization and wound healing. Exp Eye Res 1996;62(4):325-327.

48. Kim WJ, Rabinowitz YS, Meisler DM, Wilson SE. Keratocyte apoptosis associated with keratoconus. Exp Eye Res 1999; 69(5):475-481.

49. Kallinikos P, Efron N. On the etiology of keratocyte loss during contact lens wear. Invest Ophthalmol Vis Sci 2004; 45(9):3011-3020.

50. Hollingsworth JG, Efron N, Tullo AB. In vivo corneal confocal microscopy in keratoconus. Ophthalmic Physiol Opt 2005;25(3):254-260.

51. Balasubramanian SA, Pye DC, Willcox MD. Effects of eye rubbing on the levels of protease, protease activity and cytokines in tears: relevance in keratoconus. Clin Exp Optom 2013;96(2):214-218.

52. Greiner JV, Peace DG, Baird RS, Allansmith MR. Effects of eye rubbing on the conjunctiva as a model of ocular inflammation. Am J Ophthalmol 1985;100(1):45-50.

53. Fan Gaskin JC, Good WR, Jordan CA, Patel DV, McGhee CN. The Auckland keratoconus study: identifying predictors of acute corneal hydrops in keratoconus. Clin Exp Optom 2013; 96(2):208-213.

54. Grewal S, Laibson PR, Cohen EJ, Rapuano CJ. Acute hydrops in the corneal ectasias: associated factors and outcomes. Trans Am Ophthalmol Soc 1999;97:187-198.

55. Ozcan AA, Ersoz TR. Severe acute corneal hydrops in a patient with Down syndrome and persistent eye rubbing. Ann Ophthalmol (Skokie). 2007;39(2):158-160.

56. Sharma R, Titiyal JS, Prakash G, Sharma N, Tandon R, Vajpayee RB. Clinical profile and risk factors for keratoplasty and development of hydrops in north Indian patients with keratoconus. Cornea 2009;28(4):367-370.

57. McMonnies CW. Behaviour modification in the management of chronic habits of abnormal eye rubbing. Cont Lens Anterior Eye 2009;32(2):55-63.

58. García García GP, Martínez JB. Outcomes of penetrating keratoplasty in mentally retarded patients with keratoconus. Cornea 2008;27(9):980-987.

59. Lam FC, Bhatt PR, Ramaesh K. Spontaneous perforation of the cornea in mild keratoconus. Cornea 2011;30(1):103-104.

60. McMonnies CW. Intraocular pressure spikes in keratectasia, axial myopia, and glaucoma. Optom Vis Sci 2008;85(10): 1018-1026.

61. McMonnies CW, Boneham GC. Corneal curvature stability with increased intraocular pressure. Eye Contact Lens 2007; 33(3):130-137.

62. Nash IS, Greene PR, Foster CS. Comparison of mechanical properties of keratoconus and normal corneas. Exp Eye Res 1982;35(5):413-424. 